\title{
HISTORIA, TIPOLOGÍA Y FUNCIONALIDAD DE LOS CERRAMIENTOS CORALES DE LA COLEGIATA Y PARROQUIAS DE JEREZ DE LA FRONTERA
}

\author{
HISTORY, TYPOLOGY AND FUNCTIONALITY OF THE \\ CHORAL ENCLOSURES OF THE COLLEGIATE AND \\ PARISH CHURCHES OF JEREZ DE LA FRONTERA
}

\author{
Pablo J. Pomar Rodil \\ Universidad de Cádiz. España \\ ORCID: 0000-0002-0918-1739 \\ pablo.pomar@uca.es
}

\begin{abstract}
El artículo aborda el desarrollo tipológico y funcional de los cerramientos que envolvían las sillerías corales de la colegiata y demás parroquias de Jerez de la Frontera entre los siglos XVI y XIX. El estudio, que aporta un importante caudal de datos inéditos con los que se reconstruye la historia y apariencia de estas desaparecidas estructuras, se detiene especialmente en su condición de elemento arquitectónico complementario de la sillería, a la que independiza de la intromisión de seglares, al tiempo que abriga frente a las corrientes frías que incomodaban al clero, y también en otros usos de oportunidad, como el de servir de soporte de los altares secundarios dispuestos en su perímetro.

Palabras clave: coro; trascoro; Jerez de la Frontera; recinto coral.
\end{abstract}

The article deals with the typological and functional development of the enclosures that surrounded the choir stalls of the collegiate church and other parishes in Jerez de la Frontera between the 16th and 19th centuries. The study, which provides an important amount of unpublished data with which to reconstruct the history and appearance of these disappeared structures, focuses especially on their condition as an architectural element complementary to the ashlar masonry, which it makes independent of the interference of laymen, while at the same time providing shelter from the cold currents that made the clergy uncomfortable, and also on other uses, such as serving as a support for the secondary altars arranged around its perimeter.

Keywords: choir; rood screen; Jerez de la Frontera; choir enclosure. 
En el origen de los trascoros y demás cerramientos con que se envuelven las sillerías corales, más allá de razones de dignidad y ornato, que con posterioridad ciertamente serían determinantes en la renovación y ampliación de estas estructuras, encontramos la necesidad que tenía el clero de evitarse las álgidas corrientes de aire que atravesaban el templo durante las horas de rezo del oficio. Este deseo de protegerse de las bajas temperaturas, que llegó incluso a condicionar el uso de pieles en los trajes corales canonicales en sedes de clima especialmente frío y que ha dejado un animado anecdotario que bien merecería un trabajo monográfico, estuvo presente incluso en algunos de los intrincados debates que decidieron el traslado de tantos coros catedralicios españoles de la cabecera a la nave ${ }^{1}$. De esta costumbre de abrigar las sillerías corales con una cerca alta a sus espaldas habrían tenido la colegiata y parroquias jerezanas un destacado ejemplo a emular en el recinto coral de la catedral de Sevilla, donde, como contrapunto de lo dicho, también se sufría un insoportable calor en verano ${ }^{2}$.

Aunque por lo general estos cerramientos y trascoros se levantaban de cantería o ladrillo, dependiendo de los recursos económicos de la parroquia y de los materiales disponibles podían ser realizados también con maderas más o menos nobles y artísticamente labradas ${ }^{3}$. De este tipo aún se conserva, en el territorio de la antigua archidiócesis hispalense, el coro de la parroquia de Santa María de las Virtudes de Villamartín (Cádiz) ${ }^{4}$. Su pervivencia nos ayuda a intuir cuál

${ }^{1}$ En el León del siglo XVII corría un adagio popular que sostenía que para soportar el frío en su catedral "se necesitan canónigos de bronce". En 1742, cuando comienza el traslado de su sillería de la cabecera a la nave, los prebendados pensaban hacerlo en un año, que después se alargó, para "gozar en el ibierno el abrigo y commodidad de las deseadas sillas". Archivo de la Catedral de León, Actas Capitulares 1740-1744, doc. 10036, s./f., 20 de noviembre de 1742. Navascués Palacio, 1994: 89, n. 95. Teijeira Pablos, 2015: 23. Agradecemos a la Dra. María Dolores Teijeira Pablos las orientaciones y referencias que, a este respecto, generosamente ha compartido con nosotros.

${ }^{2}$ Hasta el siglo XX, durante los meses de verano, los canónigos de la catedral abandonaban el coro y rezaban el oficio en el llamado coro portátil instalado en el brazo Sur del crucero, donde la fresca corriente entre las puertas de la Lonja y de la Concepción, aliviaba a los capitulares de los rigores de la canícula sevillana. En Écija, paradigma de ciudad con verano caluroso entre las de la Archidiócesis, encontramos también una curiosa incidencia en la parroquia de Santa María en 1672, donde con frecuencia el clero abandonaba sus sitiales en los meses estivales ante las insoportables temperaturas que allí se alcanzaban, razón por la cual los beneficiados de la parroquia pidieron al visitador que se hiciesen algunas ventanas en los muros que cerraban el coro, abriéndose cuatro. Martín Pradas, 1993: 43.

3 Sobre los trascoros catedralicios españoles y sus variantes tipológicas y materiales véase Rivas Carmona, 1994; 2001: 187-204.

${ }^{4}$ En un informe de Fernando Rosales, maestro mayor de albañilería del Arzobispado, de mayo de 1796, redactado en el contexto de una importante obra de reforma del templo villamartinense, se lee que aún faltaban por ejecutarse las "paredillas" del coro. Un año 
pudo ser su apariencia y precisar los pormenores tipológicos y de diseño que los diferenciaban de las más conocidas estructuras de fábrica. Además, atendiendo a ciertos ejemplos foráneos, cabría especular también sobre cómo estas envolturas corales de madera transitaban entre la sencillez del de la iglesia mayor de Llerena (Badajoz) y el más desarrollado y arquitectónico de la catedral de Orihuela (Alicante).

Entre las parroquias jerezanas, la de San Miguel nos permite conocer, hasta donde los documentos lo hacen posible, el tránsito de un cerramiento bajo, que no había de ser más que el resultado de la dignificación de la parte trasera de su sillería con una moldura que las recorriese, a contar con otro de mayor desarrollo en altura y, con posterioridad, a la sustitución de éste por el definitivo de cantería. La primera operación tuvo lugar en 1549, cuando el carpintero de lo blanco Juan Andrés se comprometió con la fábrica a realizar un cerramiento de madera cuya altura habría de alcanzar la de unos hierros preexistentes ${ }^{5}$. Éstos suponemos que debían de ser una suerte de tirantes que irían de pilar a pilar y que servirían para suspender de ellos velos o cortinas que abrigasen el recinto. El trabajo, que debía realizarse con madera de roble, sería sencillo, pues apenas se le concedió al carpintero un mes de plazo para la colocación de los tableros, que sólo debía rematar con una cornisa que habría de reproducir la ya existente en la parte baja ${ }^{6}$. La sustitución de este cerramiento ligero por otro de fábrica tendría lugar en 1623, cuando los maestros albañiles Nicolás Ruiz Amarillo y Sebastián Ximénez se encargaron de levantar un nuevo trascoro y laterales de auténtica envergadura con las ciento cincuenta carretadas de piedra que Pedro de Tejada y Pedro Hernández debían de proporcionarles desde las canteras de El Puerto de Santa María ${ }^{7}$.

Todo hace indicar que el mismo proceso de petrificación de estructuras lignarias precedentes tuviese también lugar en San Dionisio, en torno al segundo cuarto del siglo XVII, cuando el maestro Pedro Martín Mendo realizó de cantería el trascoro y los costados, que quedarían concluidos en 1659 , y que muy

más tarde, sin haberse llegado a construir las mencionadas "paredillas", el maestro Rosales, en un nuevo informe, considera concluida la obra del coro, dando por buena, entendemos, la sustitución de esas proyectadas citaras por la envoltura de madera que aún subsiste. Falcón Márquez, 1983: 268-271. Álvarez Benítez, 2001: 77-78.

${ }^{5}$ El carpintero se obligaba a "alçar del coro que la dicha iglesia tiene de madera hasta el altura de los hieros que agora están puestos". Archivo de Protocolos Notariales de Jerez de la Frontera (En adelante APNJF). Oficio XVIII (VII). Simón García Copín. 1549, f. 720 v. Agradecemos a nuestro colega, el Dr. Manuel Romero Bejarano, su generosidad al compartir con nosotros los documentos que, con origen en el archivo de protocolos de Jerez se citan en el presente trabajo.

${ }^{6}$ APNJF. Oficio XVIII (VII). Simón García Copín. 1549, f. 720 v.

${ }^{7}$ La construcción en 1606 de una tribuna para el órgano y de la crujía en 1613 presupone a nuestro entender la paulatina consolidación del espacio coral previo. Antón Porti1lo/Jácome González, 2002: 113, 119 y 131. 
probablemente sustituyeron unas precedentes estructuras de madera ${ }^{8}$. Nos consta que así fue en San Marcos, donde en 1709 el visitador general del arzobispado, don Juan Bejarano Muñoz, ordenó que se sustituyesen por citaras de fábrica las maltrechas tablas de su viejo cerramiento coral ${ }^{9}$. La obra de construcción de este trascoro y cerramientos laterales todavía no estaría concluida en 1715, cuando el visitador don Pedro Fernández de Zurita ordenó su continuación. Para entonces, la fábrica ya contaba con los sillares que había suministrado el maestro pedrero Francisco Perea, faltando sólo la licencia del provisor para la libranza del caudal necesario para su conclusión ${ }^{10}$.

$\mathrm{Ni}$ las descripciones con que contamos del primer coro conocido de San Mateo, ni cuanto cabe interpretar de su representación gráfica en un viejo plano de sepulturas (Figura 1) conservado en su sacristía, nos permiten llegar a conclusiones irrefutables sobre si el mismo estuvo o no cerrado por citaras de fábrica o apenas con tableros de madera ${ }^{11}$. En cualquier caso, en 1717 los beneficiados tomaron la decisión -"deseando la mayor decencia y adorno de dicha iglesia, que es el medio de adquirir feligreses"- de renovar el coro siguiendo el mandato que a tal efecto les había dejado años antes el visitador don Pedro Fernández de Zurita $^{12}$. Para ello desmontaron el campanario de la vieja torre y otras obras que la fábrica había desistido de continuar, para reutilizar sus cantos en su nuevo cerramiento pétreo ${ }^{13}$.

Por aquellos años, el coro de San Lucas llevaría ya tiempo pendiente de acometer la reforma que en 1713 había ordenado el visitador Juan Bejarano Muñoz.

${ }^{8}$ Ríos Martínez, 1998: 33.

9 "Y atento a la mala disposición que tiene el choro por ser de tablas que están mui maltratadas hará zitaras en lugar de dichas tablas cuia obra se executará con intervención del vicario y veneficiados de dicha Yglesia". Archivo General del Arzobispado de Sevilla (En adelante AGAS). Sección II. Serie visitas, legajo 1350, s./f. No debió de ser el primer intento de dotar al coro de un cerramiento pétreo, pues consta en las cuentas de 1701 la adquisición por parte de la fábrica parroquial de San Marcos de once varas y media de piedra a Pedro Polanco "para las gradas del coro que se ha de azer". Sancho de Sopranis, 1935: 19-20.

10 "Que se continúe la obra comenzada en el coro de esta yglesia para que están prevenidos los cantos y materiales reconosido el costo que podrá tener para su conclusión por personas ynteligentes se haga representación al provisor para que tanteado el gasto que podrá costear esta fábrica en cada tiempo según su caudal de lizenzia para la cantidad que se puede aplicar". Sancho de Sopranis, 1936, 27, 8; Resulta y mandatos de la visita pastoral realizada por don Pedro Fernández Zurita a las parroquias de Jerez de la Frontera, octubre 1715. AGAS. Sección II. Serie visitas, libro 1359, f. 194v.

11 Pomar Rodil, 2018: 518-519.

12 Pomar Rodil, 2016: 104; 2018: 543-545.

13 Aroca Vicenti, 2002: 214, n. 82. Antón Portillo/Jácome González, 2002: 110. Pomar Rodil, 2016: 104; 2018: 518-519, 543-545. 
Entonces, además del aderezo de su maltrecha sillería, Bejarano pidió que la cercaran con citaras de ladrillo ${ }^{14}$. Sin embargo, estas solicitudes no serían atendidas ante la perspectiva del inminente inicio de las obras de renovación integral del edificio ${ }^{15}$. En 1725, aún en el contexto de esta intensa reforma, el maestro de la misma, Bartolomé Baptista, sustituyó el deteriorado cerramiento coral de madera por una nueva estructura de fábrica ${ }^{16}$. Finalmente, entre 1731 y 1732, por iniciativa del entonces cura de la parroquia, don Juan González de Silva, la cornisa de aquella citara se coronaría con las esculturas de piedra de doce profetas -en correspondencia iconográfica con los apóstoles tallados en los respaldos de la nueva sillería-, dos sibilas (Figura 2) y san Miguel batallando con el demonio, obras que han sido atribuidas a José de Mendoza ${ }^{17}$.

Conviene tener en cuenta que estas estructuras de madera que hemos visto que en San Marcos, San Lucas y quizá también en San Mateo duraron hasta el siglo XVIII, coexistieron con otros trascoros y cerramientos laterales de cantería que bien pudieron haber sido así levantados desde su origen. Parece el caso de San Juan de los Caballeros, donde el recinto coral fue realizado por Antón Martín Calafate en 1625 "de mampostería y gradas de piedra", adecuándose a las dimensiones de la rudimentaria sillería preexistente, que llevaría en el tramo de los pies del templo, como mucho, unos treinta años, dado que la bóveda que lo cubre no se cerró hasta $1591^{18}$. Otro, el de Santiago, levantado en 1565 por el cantero Melchor López, estaba jalonado por veinticuatro pilastras, intuyéndose por tanto que fuese una obra que participase del lenguaje clásico. ${ }^{19}$

14 "Que atento a que el coro de esta yglesia es todo de madera que por antiguo está tan maltratado que se está cayendo; procure el mayordomo luego que la fábrica tenga caudal para ello cercarlo de citaras con ladrillo, aderezando y componiendo las sillas y bancos de él». Mandatos de la visita pastoral realizada por don Juan Bejarano Muñoz a las parroquias de Jerez de la Frontera, enero-febrero 1713. AGAS. Sección II. Serie visitas, legajo 1354, f. 504 r.

${ }^{15}$ Sobre la reforma de San Lucas, que transformó el templo mudéjar en epitelialmente barroco, véase Moreno Arana, 2016: 105-136.

16 Aroca Vicenti, 2002: 196.

${ }^{17}$ Pese a que, en la década de los sesenta del pasado siglo, el conjunto coral fue lamentablemente desmantelado, aún perviven almacenadas sus esculturas, en discreto estado de conservación. Moreno Arana, 2014: 194; 2016: 124. Aroca Vicenti, 2002: 197. Repetto Betes, 1978: 248, n. 1; Álvarez Luna/Guerrero Vega/Romero Bejarano, 2003: 269. Mariscal Rodríguez/Pomar Rodil, 2004: 78-79.

18 Mesa Ginete, 1888: II, 150. Antón Portillo/Jácome González, 2002: 101-137. Mariscal Rodríguez/Pomar Rodil, 2004: 63.

${ }^{19}$ El compromiso del cantero Melchor López con el mayordomo de la fábrica de San Mateo, don Rodrigo Pérez, en 1565 se concretaba en la entrega de 150 varas de piedra de Peña de Barguetas "para hazer un coro en la dicha yglesia de señor Santiago", que debía 
En el último cuarto del siglo XVIII se levantaría el cerramiento del coro de la nueva colegiata (Figuras 3 y 4). De incipiente neoclasicismo en cuanto a sus elementos arquitectónicos, en lo decorativo aún mantenía golpes de talla rococó ${ }^{20}$. Su labrado, realizado de cantería como todo el edificio, corrió a cargo del genovés Jacome Bacaro, quien recibió en septiembre de 1778 el primer pago a cuenta por estos trabajos que habrían de concluir con la inauguración del templo a finales de aquel año. Lamentablemente, en la actualidad se encuentra desmantelado, como todo el conjunto coral ${ }^{21}$.

Estas estructuras de cerramiento, si bien al caer sobre los tableros de respaldo de las sillas de coro casi carecían de proyección interior salvo a nivel de cornisas, hacia el exterior podían ser soporte parietal de altares con sus pequeños retablos, de los que conocemos la advocación de algunos. En el trascoro de la vieja colegiata se situaba un altar dedicado a la Virgen, bajo las sucesivas advocaciones de los Remedios y de los Reyes ${ }^{22}$. En el del nuevo templo se ubicó un retablo rococó presidido por un lienzo de san Cristóbal y en sus cerramientos laterales el de la compatrona de la ciudad, la Virgen de Consolación, con una hornacina sobre ella con un Ecce Homo de terracota, en el lado de la epístola; y otro con una delicada pintura de la Virgen con el Niño en el del evangelio ${ }^{23}$. También en el trascoro de la parroquia de San Lucas, inmediato a la puerta principal del templo, se ubicó un pequeño altar dedicado a San Cristóbal (Figura 5). En este caso un relieve pétreo policromado, que aún se conserva embutido en el muro del lado del evangelio $^{24}$. Entre las noticias dispersas que aporta la documentación se localizan los altares de San Antonio Abad, en el trascoro de San Miguel; del Santo Cristo, en San Juan de los Caballeros; de Nuestra Señora del Dolor, de pintura, en San Marcos; y otro, cuya iconografía desconocemos, que se estaba dorando en 1659 en el

contar con "veynte e quatro colunas quadradas de a dos varas de altura cada una [y] de grueso palmo e medio". APNJF. Oficio XVIII. Juan Sánchez. 1565, f. 183 v.

${ }^{20}$ Repetto Betes, 1978: 249.

${ }^{21}$ Repetto Betes, 1978: 249. Álvarez Luna/Guerrero Vega/Romero Bejarano, 2003: 144-159.

22 Jiménez López de Eguileta/Pomar Rodil 2014: 475.

${ }_{23}$ Pescador y Gutiérrez del Valle, 1906:118. Repetto Betes, 1978: 157-158.

${ }^{24}$ La coincidencia en el calendario del día de San Cristóbal con el de Santiago el Mayor, que propició que en España el primero no se celebrase ni siquiera como conmemoración litúrgica, no fue óbice para que en nuestra patria su devoción fuese superlativa desde la Edad Media, siendo frecuentemente representado -como vemos en Jerez- en las inmediaciones de las puertas y atrios de los templos, donde con facilidad era localizable visualmente, dado que, según la supersticiosa creencia popular, bastaba con mirar su imagen para permanecer durante todo el día a salvo de morir repentinamente y sin confesión. Interián de Ayala, 2000: II, III, 355-356. Jaquero Esparcia, 2016: 247; 2020. 
trascoro de la parroquia de San Dionisio ${ }^{25}$. No obstante, a diferencia de cuanto sucedía en algunas catedrales, donde con frecuencia un altar situado en el trascoro focalizaba el amplio espacio existente entre éste y el testero occidental, desarrollando un espacio celebrativo adicional, la ubicación frecuente de estos coros parroquiales a los pies del templo impidió tales derivadas funcionales.

El cerramiento coral de la nueva colegiata contaba con seis postigos, dos en el trascoro y otros tantos en cada uno de los costados, pero dos de estos últimos no conectaban el interior del coro con las naves laterales, sino que daban servicio desde estas a la escalera de la tribuna y a una minúscula estancia de uso incierto. Esto no suponía una novedad, pues quedaba con frecuencia, entre citara y sillería, el espacio suficiente para albergar estas pequeñas cámaras de servicio. En las parroquias jerezanas resultaba singular el aposento ubicado en el trascoro de la de Santiago, que contaba con un pozo que servía para la limpieza y refrescado del templo ${ }^{26}$. También llama la atención la cámara surgida bajo la tribuna del órgano cuando, clausurada la puerta mayor de San Mateo, el coro se arrimó a la misma, que se destinó a archivo parroquial ${ }^{27}$. Y, por último, el cerramiento coral del lado de la epístola de la parroquia de San Miguel, que albergaba, también bajo el órgano, la librería de coro donde se guardaban los cantorales, procesionarios, breviarios y demás libros de uso de beneficiados y capellanes ${ }^{28}$.

Para concluir, es necesario señalar que, además de resguardar de las corrientes y proteger del frío, estos cerramientos contribuyeron a la decorosa separación entre los clérigos que asistían al coro y los seglares congregados en el templo, proporcionando a los primeros un espacio adecuado para recitar el oficio sin las incomodidades y molestias propias del trasiego de fieles. De hecho, evitar la entrada de seglares en el coro alcanzó a ser una preocupación recurrente de la que queda testimonio en constituciones sinodales y estatutos capitulares, así como en mandatos de visitas y otras acciones de gobierno de numerosas diócesis ${ }^{29}$. En la de Se-

${ }^{25}$ AGAS. Sección II, serie visitas, legajo 1443, s./f.; legajo 1367, f. 480v; y Sección IV. Serie 13, legajo 1421. Ríos Martínez, 1998: 33.

${ }^{26}$ En la descripción del templo existente en la resulta de la visita de 1673 por don Gonzalo de Mier y Barreda consta que "Detrás del coro está un aposento en el cual está un pozo para el aseo y riego de la iglesia”. AGAS Sección II, visitas, legajo 1443, s./f.

${ }^{27}$ La ubicación del archivo de San Mateo en este lugar la conocemos a través de un mandato del licenciado Varo y Guerrero, que ordenó en 1725 «que se suele el quarto que esta a espaldas del coro dedicado para archivo de papeles de esta iglesia». AGAS. Sección II. Serie visitas, legajo 1367, ff. 470r.-470v. Creemos que pudiera ser el mismo que siete años antes se mandó enmaderar. Aroca Vicenti, 2002: 241, n. 83.

${ }_{28}$ Don Gonzalo de Mier y Barreda, en la precitada visita de 1673, al describir la parroquia de San Miguel, precisa: "Y a un lado del coro está un aposento que cae debajo del órgano donde se guardan los libros de canto que son 14 y 12 libros procesionarios y dos breviarios de cámara entera y otros libros”. AGAS. Sección II, visitas, legajo 1443, s./f.

${ }^{29}$ Teijeira Pablos, 2015: 22-24. 
villa, el cardenal don Rodrigo de Castro dio a la catedral, en febrero de 1584, una suerte de ordenanzas que restringían y regulaban el mencionado acceso de los seglares al recinto coral ${ }^{30}$. En su preámbulo se describía la poco edificante situación que motivó su redacción: "Por cuanto de entrar los legos en los choros donde se cantan los divinos oficios se sigue muchas veses que no se disen con tanta atención y devoción como convendría, assi por el ruido que hassen parlando unos legos con otros y que son ocassion que tambien los eclesiasticos que an de cantar el dicho Oficio Divino parlen con ellos, como para los cumplimientos que hacen dexándoles sus sillas por ser personas de autoridad son causa de interrumpir los oficios que an començado" ${ }^{11}$. Estas ordenanzas aparecen también recogidas en las Constituciones Sinodales del cardenal Fernando Niño, de 1609, donde se especifica que han de extenderse al resto de iglesias del arzobispado, mandando que ningún seglar permaneciese en el coro durante el rezo del oficio ${ }^{32}$. Los visitadores velaron continuamente por el cumplimiento del mandato sinodal en el ámbito jerezano que nos ocupa. Fue el caso de don Luis de Castro Farfán, que ordenó a la parroquia de San Marcos, en mayo de 1646, "que ningún seglar de qualquier estado y condición que sea se siente en el coro mientras los divinos oficios se celebren, ni los beneficiados lo consientan" ${ }^{33}$. De todo ello darían razón los Estatutos del cabildo jerezano en 1648, señalando "que al tiempo que las horas canónicas y los divinos oficios se dijeren y celebraren [...], las personas seglares no estén en el coro entre dichos canónigos en las sillas altas ni bajas" ${ }^{34}$. Aún así, por razones de mera funcionalidad y comodidad, los cerramientos contaban con frecuencia con postigos abiertos a las naves laterales o al trascoro para que los beneficiados, capellanes y mozos pudieran entrar y salir del recinto sin tener que hacerlo por su parte frontal, frecuentemente dotada de reja. Inevitablemente, si aquellos vanos no contaban con sus correspondientes batientes de madera -como los artísticamente labrados de la colegiata-o con cancelas -como las que se aprecian en el ya mencionado plano de sepulturas de San Mateo-, e incluso si aun contando con ellos no se estaba atento a que permaneciesen cerrados, con frecuencia solían ser aprovechados por los feligreses para entrar indebidamente en el recinto. De ello

${ }^{30}$ Archivo de la Catedral de Sevilla (En adelante ACS). Sección III. Libro 53, doc. 1.

31 ACS. Sección III. Libro 53, doc. 1.

32 "que ningún lego (si no fuere cantor o ministro de la iglesia) entre ni esté en el coro mientras se dicen los divinos Oficios, excepto los señores de título y los oidores de los Consejos y Audiencias Reales de Su Majestad, y los comendadores de las Órdenes Militares, so pena de excomunión mayor" Constituciones del Arzobispado de Sevilla, 1864: II, 28.

33 "Que ningún seglar de qualquier estado y condición que sea se siente en el coro mientras los divinos oficios se celebren ni los beneficiados lo consientan". Archivo Histórico Diocesano de Jerez de la Frontera (En adelante AHDJF). Fondo parroquial. San Marcos. Fábrica. Visitas I, 11-A, f. 158 r.

${ }^{34}$ Estatutos y constituciones, 1648: 28. 
ya habían dado razón los Estatutos viejos del Cabildo Colegial en 1484. En ellos se ordenaba que los postigos del coro de la colegiata permaneciesen cerrados para evitar que las personas paseasen por el recinto "como por calle pública", distrayendo y confundiendo a los beneficiados, que se equivocaban con los versos y entonaciones del canto ${ }^{35}$.

Fecha de recepción: 30 de octubre de 2020.

Fecha de aceptación: 17 de marzo de 2021.

\section{BIBLIOGRAFÍA}

Álvarez Benítez, José Manuel (2001): Guía histórico-turística del templo de Santa María de las Virtudes de Villamartín. En el año 500 de la fundación del pueblo. Villamartín: Ayuntamiento de Villamartín.

Álvarez Luna, María de los Ángeles/Guerrero Vega, José María/Romero Bejarano, Manuel (2003): La intervención en el patrimonio. El caso de las iglesias jerezanas. Jerez de la Frontera: Ayuntamiento de Jerez de la Frontera.

Antón Portillo, Jesús/Jácome González, José (2002): "Apuntes histórico-artísticos de Jerez de la Frontera en los siglos XVI-XVIII ( $3^{\text {a }}$ serie)". En: Revista de Historia de Jerez, 8, pp. 101-137.

Aroca Vicenti, Fernando (2002): Arquitectura y urbanismo en el Jerez del siglo $X$ VIII. Jerez de la Frontera: Centro Universitario de Estudios Sociales.

Constituciones del Arzobispado de Sevilla hechas y ordenadas por el Ilustrísimo y Reverendísimo Sr. D. Fernando Niño de Guevara, Cardenal y Arzobispo de la Santa Iglesia de Sevilla, en el Sínodo que celebró en su Catedral año de 1604; y mandadas imprimir por el Deán y Cabildo, Canónigos in Sacris, Sede vacante, en Sevilla, año de 1609 (1862-1864): Sevilla: Francisco Álvarez y C. ${ }^{\text {. }}$

Estatutos, y constituciones de la santa Iglesia colegial de nuestro Señor san Salva$\operatorname{dor}(1648):$ s./l.: s./n.

35 "Iten, porque una de las principales cabsas por que en el dicho coro quando las oras se dizen e cantan non se ha guardado nin guarda silencio ha seido e son e a ello han dado e dan ocasión los dos postigos que han estado abiertos en principio del coro por donde de continuo entrauan e salían e pasauan los legos omes e mugeres, moços e esclauos e passauan por el dicho coro como por calle pública, por lo qual muchas uezes dauan turbación a los beneficiados e les fazían errar los uersos e el canto en grand confusión e menosprecio de nuestro Sennor, por ende, por euitar estos inconuenientes e otros semeiantes, mandamos que los dichos postigos estén siempre cerrados como agora están, en manera que non se puedan abrir nin por ellos pueda entrar nin salir persona alguna". AHDJF, Fondo Colegial, sec. I, caja 9, doc. 1.1. Recientemente ha visto la luz una cuidada edición de estos estatutos: Jiménez López de Eguileta, 2019. 
Falcón Márquez, Teodoro (1983): Iglesias de la Sierra de Cádiz. Cádiz: Caja de Ahorros de Cádiz.

Interián de Ayala, Fray Juan (1930): Pictor christianus eruditus sive De erroribus qui passim admittuntur circa pingendas atque effingendas sacras imagines. Madrid: Tipografía del Convento de la Merced.

Jaquero Esparcia, Alejandro (2016): "El control de la religiosidad popular a través de los tratados pictóricos en el Siglo de Oro: Los casos de las imágenes de San Cristóbal y La Verónica”. En: Peinado Guzmán, José Antonio/Rodríguez Miranda, María del Amor: Meditaciones en torno a la devoción popular. Montilla: Asociación Hurtado Izquierdo.

(2020): "La poesía religiosa al servicio de la pintura: lecturas contrarreformistas en torno a san Cristóbal”. En: e-Spania, 37 [https://doi.org/10.4000/espania.36373].

Jiménez López de Eguileta, Javier E./Pomar Rodil, Pablo J. (2014): "La colegiata medieval de San Salvador de Jerez de la Frontera". En: 750 aniversario de la incorporación de Jerez a la Corona de Castilla: 1264-2014. Jerez de la Frontera: Ayuntamiento de Jerez de la Frontera, pp. 459-484.

Jiménez López de Eguileta, Javier (2019): "Los estatutos medievales del cabildo colegial de Jerez de la Frontera (1484)". En: Pardo Rodríguez, María Luisa: Iglesia y Escritura en Castilla. Siglos XII-XVII. Sevilla: Universidad de Sevilla, pp. 241-275.

Mariscal Rodríguez, Miguel Á./Pomar Rodil, Pablo J. (2004): Jerez. Guía artística y monumental. Madrid: Sílex Ediciones.

Martín Pradas, Antonio (1993): Las sillerías de coro en parroquias y conventos ecijanos. Écija: Gráficas Sol.

Mesa Ginete, Francisco de (1888): Historia Sagrada y Política de la Muy Noble y Muy Leal Ciudad de Tarteso, Turdeto, Asta Regia, Asido Cesariana, Asidonia, Gera, Jerez Sidonia, hoy Jerez de la Frontera. Jerez de la Frontera: Melchor García Ruiz.

Moreno Arana, José Manuel (2014): “San Miguel Arcángel”. En: Jiménez López de Eguileta, Javier E./Pomar Rodil Pablo J. (eds.): Limes Fidei. 750 años de Cristianismo en Jerez. Jerez de la Frontera: Diócesis de Asidonia-Jerez, pp. 194-195.

(2016): "La transformación barroca de la iglesia de San Lucas de Jerez en el siglo XVIII”. En: Aroca Vicenti, Fernando/Pérez Mulet, Fernando (Eds.): Nuevas aportaciones a la Historia del Arte en Jerez de la Frontera y su entorno. Cádiz: Universidad de Cádiz, pp. 105-136.

Navascués Palacio, Pedro (1994): "El coro y la arquitectura de la Catedral. El caso de León". En: Gutiérrez Robledo, José Luis/Navascués Palacio, Pedro: Medievalismo y neomedievalismo en la arquitectura española: Las catedrales de Castilla y León. Ávila: Fundación Cultural Santa Teresa, pp. 53-94. 
Pescador y Gutiérrez del Valle, Mariano (1906): Los pintores jerezanos. Sanlúcar de Barrameda: Imprenta de Ardibio Pulet.

Pomar Rodil, Pablo J. (2016): "Los feligreses y el templo. Espacio arquitectónico, liturgia y cura de almas". En: Aroca Vicenti, Fernando/Pérez Mulet, Fernando (Eds.): Nuevas aportaciones a la Historia del Arte en Jerez de la Frontera y su entorno. Cádiz: Universidad de Cádiz, pp. 79-104.

(2018): “«El medio de adquirir feligreses». Liturgia parroquial y espacio arquitectónico en la iglesia de San Mateo de Jerez de la Frontera". En: Jiménez López de Eguileta, Javier E. (Ed.): La parroquia de San Mateo de Jerez de la Frontera. Historia, arte y arquitectura. Murcia: Universidad de Murcia, pp. 505-545.

Réau, Louis (2000): Iconografía del arte cristiano. Barcelona: Ediciones del Serbal.

Repetto Betes, José Luis (1978): La obra del templo de la Colegial de Jerez de la Frontera. Cádiz: Diputación de Cádiz.

Ríos Martínez, Esperanza de los (1998): "La parroquia jerezana de San Dionisio durante el siglo XVII: Sus relaciones con el Cabildo Municipal”. En: Revista de Historia de Jerez, 4, pp. 31-36.

Rivas Carmona, Jesús (2001): "El trascoro: de muro a capilla". En: Yzquierdo Perrín, Ramón: Los coros de catedrales y monasterios: arte y liturgia. La Coruña: Fundación Pedro Barrié de la Maza. La Coruña, 2001, pp. 187-204.

(1994): Los trascoros de las catedrales españolas: estudio de una tipología arquitectónica. Murcia: Universidad de Murcia.

Sancho de Sopranis, Hipólito (1935): "Papeletas para una serie de artistas regionales". En: Guión, pp. 18-21.

(1936): "Papeletas para una serie de artistas regionales (segunda serie)". En: Guión, pp. 23-27.

Teijeira Pablos, María Dolores (2015): "«Aziendo presbiterio mui capaz». El «Modo español» y el traslado de coros góticos en la España moderna”. En: AA.VV.: Choir Stalls in Architecture and Architecture in Choir Stalls. Cambridge: Cambridge Scholars Publishing, pp. 1-26. 


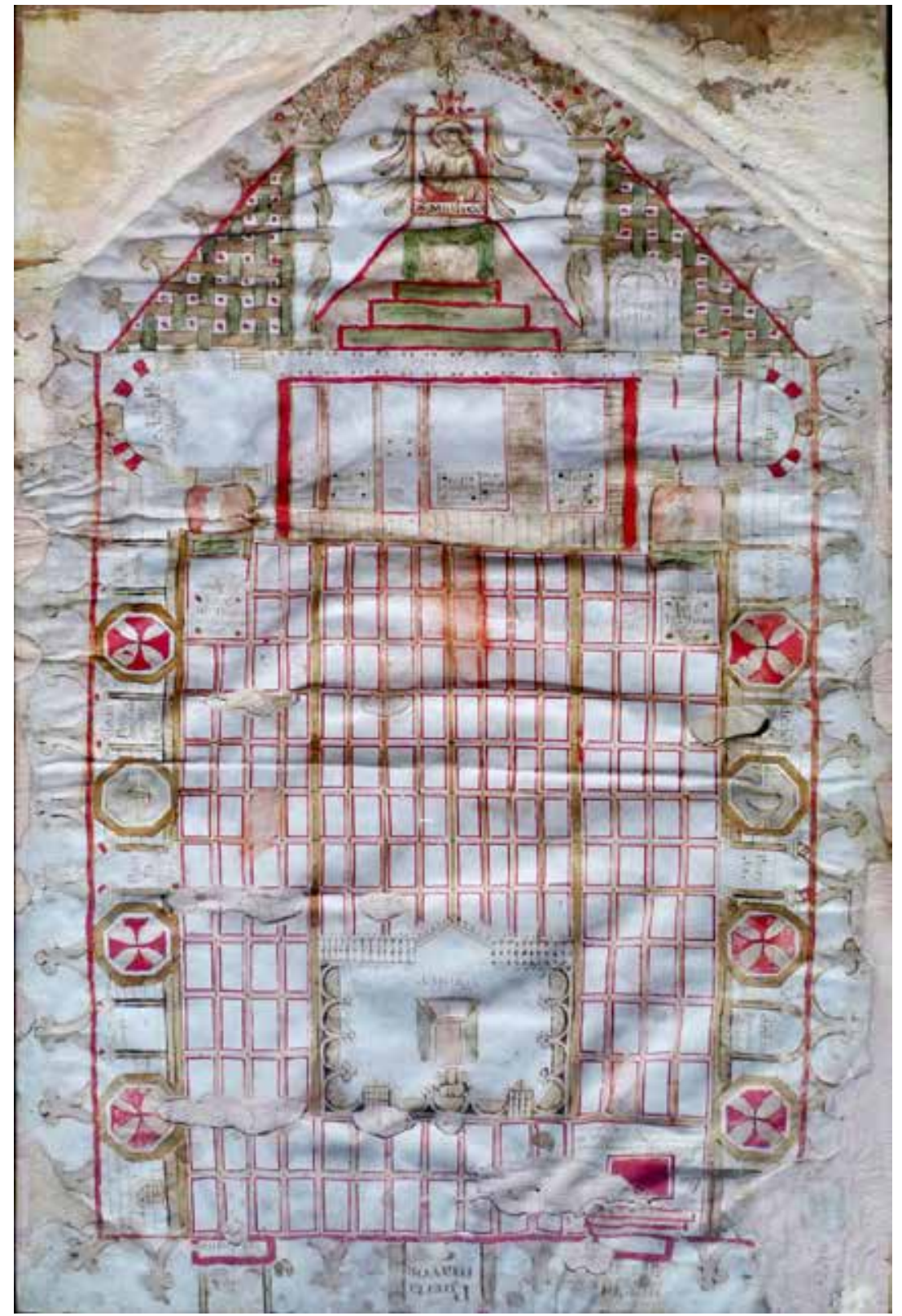

Figura 1. Anónimo. Plano de sepulturas. S. XVII. Parroquia de San Mateo. Jerez de la Frontera. 


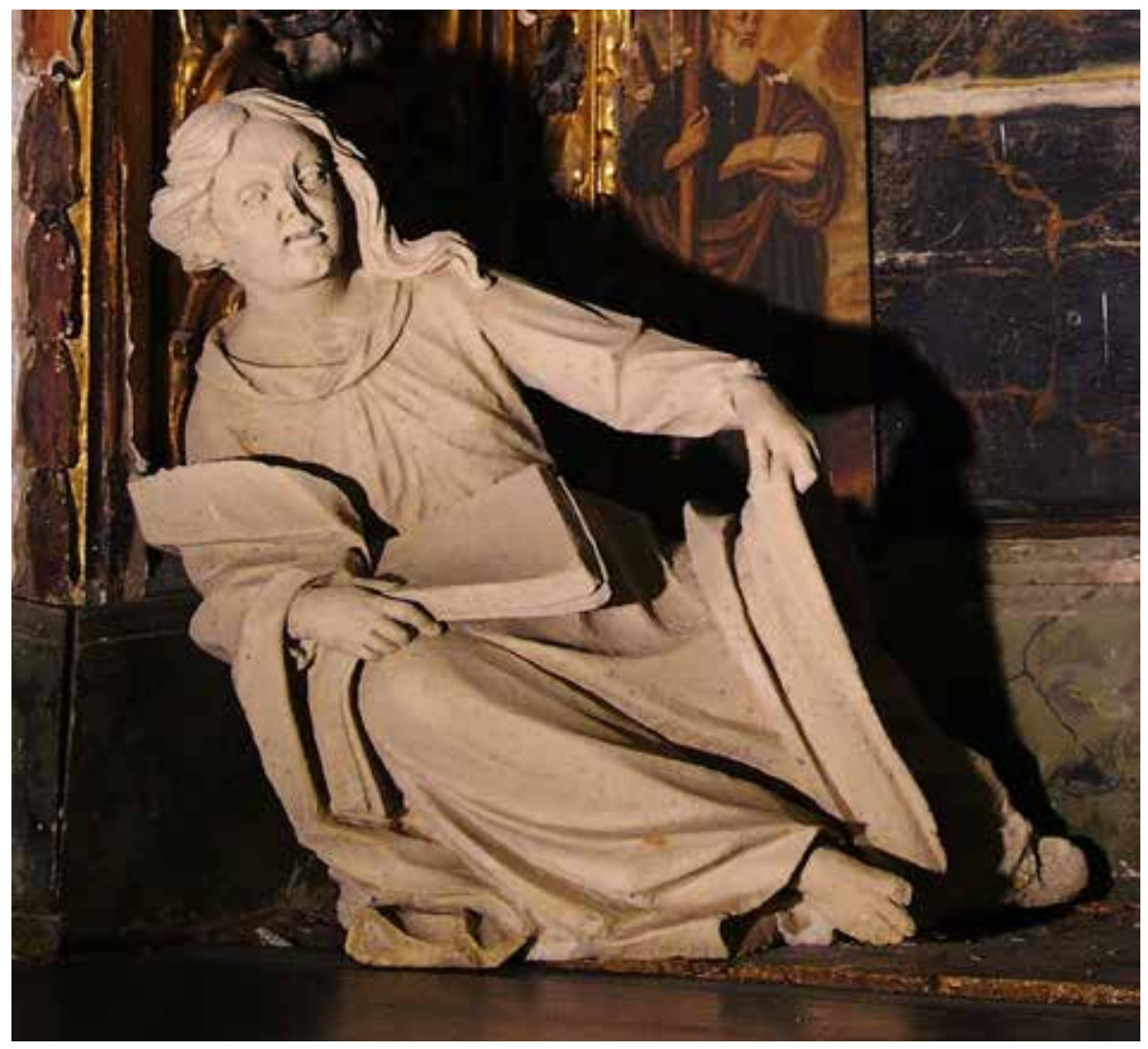

Figura 2. José de Mendoza (Atribuido). Sibila. 1731-1732. Parroquia de San Lucas. Jerez de la Frontera. 


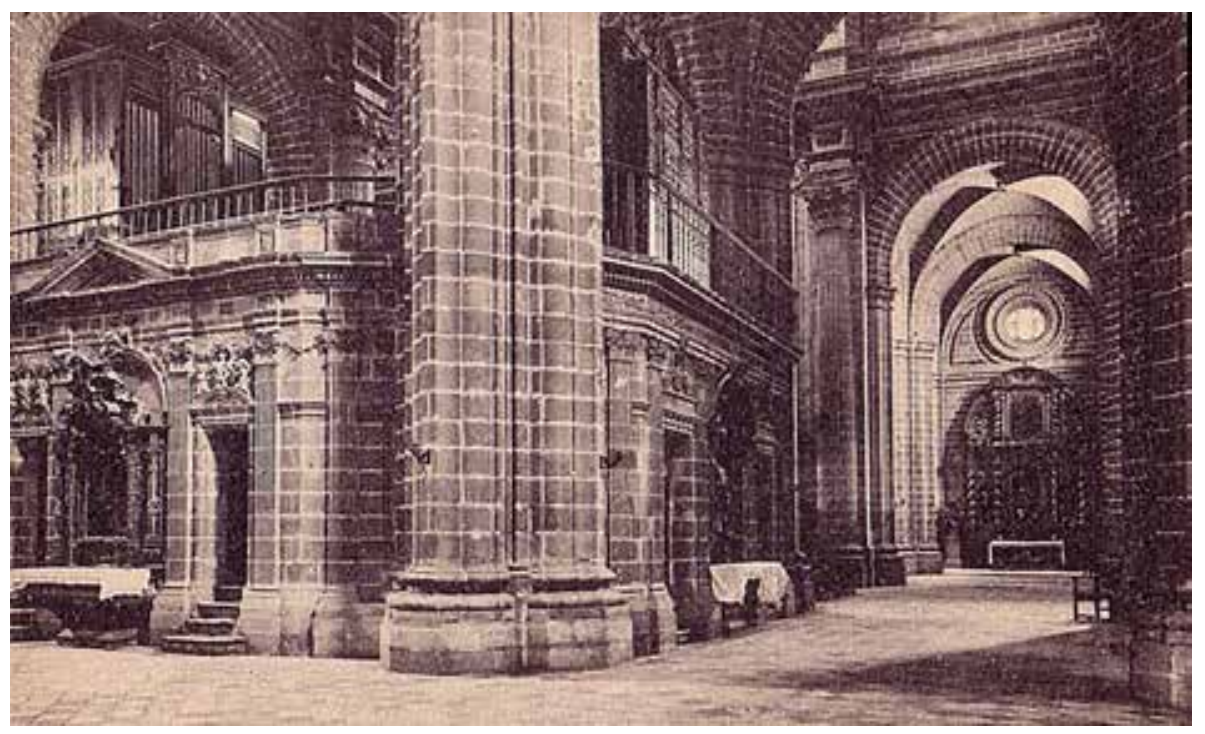

Figura 3. Jacome Bacaro. Cerramiento coral. 1778. Colegiata de San Salvador. Jerez de la Frontera. 


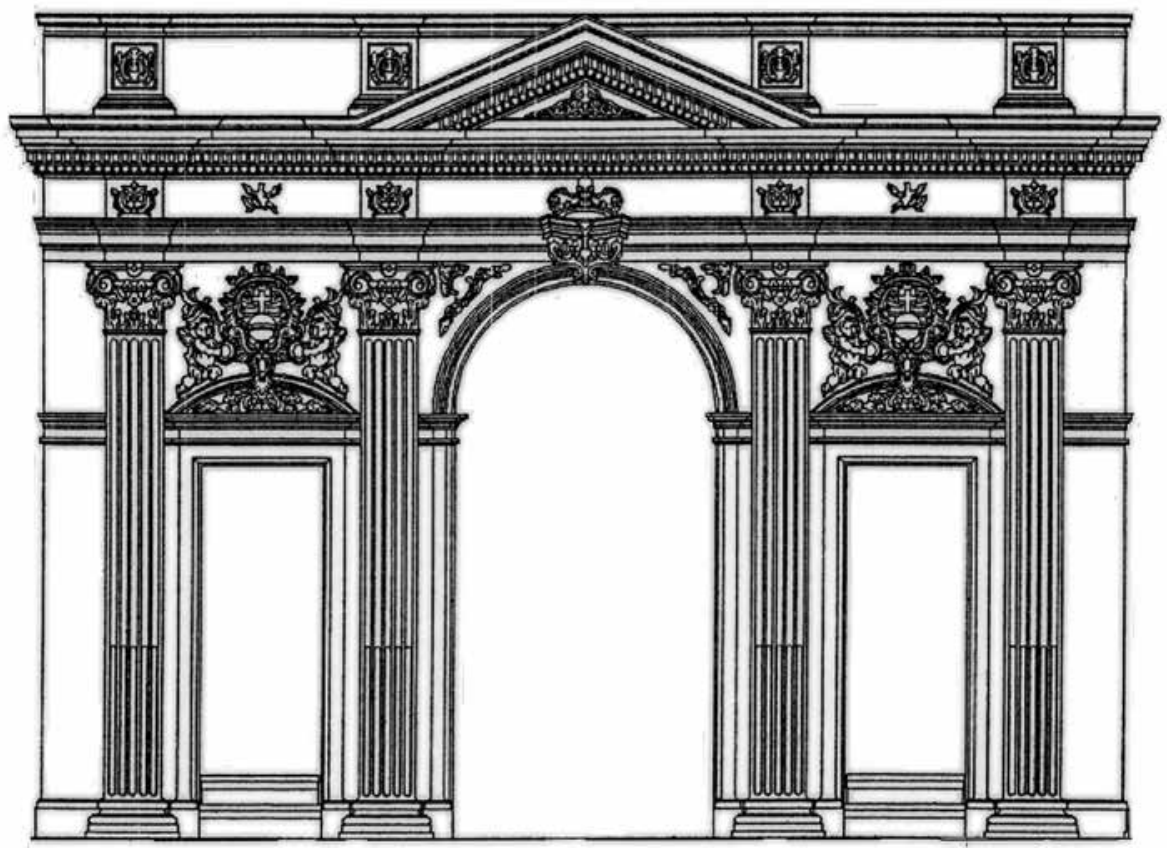

Figura 4. Jacome Bacaro. Trascoro. 1778. Colegiata de San Salvador. Jerez de la Frontera. Dibujo de Pablo Diáñez Rubio. 


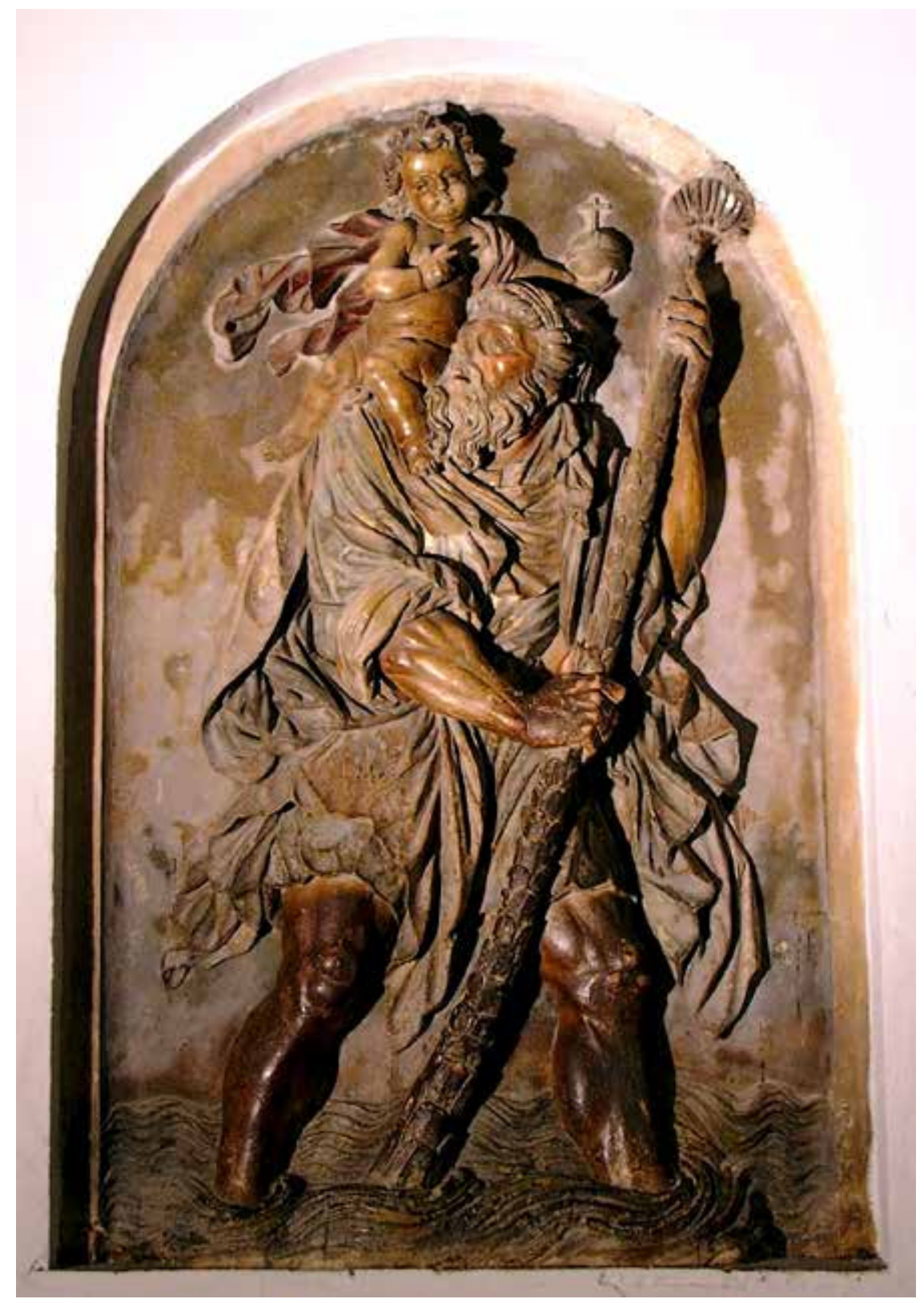

Figura 5. José de Mendoza (Atribuido). San Cristóbal. 1731-1732. Parroquia de San Lucas. Jerez de la Frontera. 